



\section{Revista de Sociología}




\section{Decano de la Facultad de Ciencias Sociales}

Marcelo Arnold

\section{Director del Departamento de Sociología}

Claudio Duarte

\section{Director de la Revista}

Octavio Avendaño

\section{Asistente Editorial}

Javier Loyola

\section{Comité Local}

Raúl Atria. Universidad de Chile Emmanuelle Barozet. Universidad de Chile Manuel Antonio Garretón. Universidad de Chile Aldo Mascareño. Universidad Alberto Hurtado Leonardo Mazzei. Universidad Andrés Bello

Carlos Ossandón. Universidad de Chile José Ossandón. Universidad Diego Portales

Carlos Ruiz Sch. Universidad de Chile

María Emilia Tijoux. Universidad de Chile Manuel Tironi. Pontificia Universidad Católica

\section{Comité Internacional}

Guy Bajoit. Université Catholique de Louvain. Bélgica Fernando Calderón. Programa de Naciones Unidas para el Desarrollo (PNUD). Argentina

Daniel Chernilo. Loughborough University. Inglaterra Julio Cotler. Instituto de Estudios Peruanos. Perú José Mauricio Domingues. Universidade Federal do Río de Janeiro. Brasil

Francois Dubet. Université Victor Segalen Bordeaux 2. Francia

David Lehmann. University of Cambridge. Inglaterra Danilo Martuccelli. Université Lille 3. Francia

Fernando Mires. Universität Oldemburg. Alemania

Guillermo O'Donnell. Universidad de San Martín. Argentina

Leigh Payne. University of Oxford. Inglaterra

Alejandro Portes. Princeton University. Estados Unidos

Bryan Roberts. University of Texas-Austin. Estados Unidos

Maria Luisa Tarrés. Colegio de México. México

Carlo Trigilia. Università degli studi di Firenze. Italia

Maurice Zeitlin. University of California. Estados Unidos

La Revista de Sociología es publicada por el Departamento de Sociología perteneciente a la Facultad de Ciencias Sociales de la Universidad de Chile.

Las opiniones vertidas en los artículos publicados son de exclusiva responsabilidad de sus autores.

Av. Capitán Ignacio Carrera Pinto 1045, Ñuñoa, Santiago de Chile

Teléfono: (0056 2) 9787782

Fax: (0056 2) 9787777

E-mail: revsoc@uchile.cl 


\section{Índice}

11

13

31

57

59

87

125

151

165

167

179

199

219

221

DEMOCRACIA, REPRESENTACIÓN Y DESEMPEÑO INSTITUCIONAL PRESENTACIÓN

SECCIÓN I * TEMA CENTRAL

Instituciones y gobernabilidad

Acuerdos de gobernabilidad para la sostenibilidad: una perspectiva regional Phillipe C. Schmitter

Variación en la fortaleza institucional

Steven Levitsky y María Victoria Murillo

SECCIÓN II * TEMA CENTRAL

Rendición de cuentas y democracia directa

Fora Collor / Que se vayan todos: Episodios de accountability en Argentina y Brasil

Inés M. Pousadela

Las instituciones de democracia directa a nivel nacional en América Latina.

Balance comparado: 1978-2010

Daniel Zovatto

SECCIÓN III * TEMA CENTRAL

Liderazgo carismático y populismo

El liderazgo político en democracias de baja institucionalización (el caso del peronismo en la Argentina)

María Matilde Ollier

El lenguaje populista en el poder

Donatella Campus

SECCIÓN IV * TEMA CENTRAL

Proceso político y sistema de representación en Chile

El giro hacia la derecha en las últimas elecciones chilenas

Octavio Avendaño

Continuidades y cambios de la Matriz Sociopolítica en Chile

desde la reinauguración democrática

Gloria de la Fuente

Tecnocracia y democracia en el Chile contemporáneo: el caso

de los gobiernos de la Concertación (1990-2010)

Mireya Dávila A.

SECCIÓN V*TEMA CENTRAL

Bicentenario

El Bicentenario en México: la historia desde la política

Nora Rabotnikof

\section{DEPARTAMENTO DE SOCIOLOGÍA \\ FACULTAD DE CIENCIAS SOCIALES • UNIVERSIDAD DE CHILE}





\section{Presentación}

Este número de la Revista de Sociología ha sido organizado con trabajos seleccionados de las ponencias presentadas al XXI Congreso Mundial de Ciencia Política, realizado en Santiago entre los días 12 y 16 de julio del 2009, y que fue organizado por la Internacional Political Science Association (IPSA). Recopila algunos de los debates y diagnósticos más relevantes acerca de las democracias actuales, en especial de aquellas que iniciaron sus procesos de construcción y reconstrucción hace ya cuatro décadas. Para ello se ha privilegiado la mirada global, regional y local acerca de aquellos fenómenos que acompañan el devenir de muchas de estas democracias.

Son diversos los desafíos que enfrentan las democracias contemporáneas para lograr niveles de inclusión y un funcionamiento adecuado de sus instituciones, acorde con los principios de libertad y protección de los ciudadanos. Como evidencian una serie de estudios e informes internacionales, existe una situación de diferenciación respecto del funcionamiento efectivo de las instituciones democráticas, sus grados de legitimidad y el nivel de participación en los asuntos públicos por parte de los más variados sectores de la sociedad. Si bien muchas de las dificultades que enfrentan las democracias también se constatan en aquellas consideradas más avanzadas, las posibilidades de proyección y profundización aparecen mucho más limitadas entre las originadas a partir de los procesos de transición que tuvieron lugar desde la segunda mitad de los años setenta.

La Revista ha sido organizada en función de cinco secciones, que van desde el funcionamiento de las instituciones democráticas hasta temas relacionados con la identidad y la memoria colectiva. En la primera sección, sobre instituciones y gobernabilidad, se presentan un artículo de Philippe C. Schmitter y otro escrito por Steven Levitsky y María Victoria Murillo. El texto de Schmitter parte dando cuenta de aquellas tendencias que vienen experimentando los Estados y las democracias en las últimas décadas, como consecuencia del predominio de una serie de fuerzas globales. Tales fuerzas, que se expresan en el peso que adquieren los actores no estatales, como las empresas trasnacionales, o desde otro ángulo el terrorismo internacional, debilitan la soberanía y el poder de decisión de los sistemas políticos a escala nacional. Tras la entrega de estos antecedentes, Schmitter se detiene a analizar la importancia que adquieren las instituciones y los gobiernos supranacionales, concentrándose en la experiencia de la Unión Europea. A partir de las discusiones sobre temas ambientales y de desarrollo sostenible, expone el funcionamiento de las instituciones y las instancias deliberativas a escala supranacional, la forma en que éstas se relacionan con los Estados y los mecanismos de control que se han venido promoviendo desde los órganos centrales y representativos de la Unión.

En el segundo artículo, Levitsky y Murillo examinan el funcionamiento de las instituciones políticas en los procesos de democratización más recientes. Se trata de un artículo bastante aportativo para entender la condición de las democracias de América Latina y Europa del Este, ya que se analizan las causas y consecuencias de la debilidad interinstitucional. Según afirman los autores, no en todos estos países existe una situación de debilidad institucional sino que 
se dan más bien variaciones; es decir, existen instituciones que funcionan bien en algunos ámbitos pero que tienen un desempeño deficitario en otros y viceversa. Levistky y Murillo explican que las instituciones formales suelen nacer débiles "porque los actores que las crean carecen de interés en hacerlas cumplir (...) o porque carecen de la capacidad para hacerlas cumplir...". Normalmente las instituciones devienen en decorativas cuando las élites toman prestado un determinado modelo institucional como respuesta a expectativas internacionales o, simplemente, por depender de la asistencia internacional. También puede ocurrir que exista la intención de alcanzar metas morales o simbólicas, pero sin que necesariamente las normas se cumplan, como ocurre con la legislación antidivorcio y antiaborto. Por el contrario, hay otros factores que influyen favorablemente en la estabilidad institucional y en el reconocimiento de las normas, como la influencia que alcanzan determinados grupos o sectores organizados. Los autores incluyen además una reflexión acerca de la variación institucional para los estudios e investigaciones comparadas. Por último, plantean que las variaciones se transforman en un importante estímulo para un estudio en profundidad del desarrollo y el cambio institucional.

La segunda sección presenta dos artículos sobre rendición de cuentas y democracia directa, respectivamente. El primer artículo corresponde a un trabajo de Inés Pousadela acerca del funcionamiento de la rendición de cuentas - O accountability-, en el que se comparan los procesos que antecedieron a la caída de los gobiernos de Collor de Mello en Brasil y de De la Rúa en Argentina. A juicio de Pousadela, las formas de accountability ejercidas desde la participación y la competencia política se hacen más efectivas cuando se entrelazan con mecanismos horizontales, derivados de una adecuada división de poderes y de la función desempeñada por determinadas agencias estatales. Las dos experiencias gubernamentales señaladas estuvieron precedidas por situaciones de corrupción y debilitamiento institucional, generadas durante los años ochenta y noventa, respectivamente. Entre las diferencias detectadas por la autora, se constata que en Brasil la accountability legal u horizontal logró ser efectiva sólo cuando se activaron los mecanismos de accountability electoral o social. En Argentina, la fuerza alcanzada por la accountability electoral y social se tradujo en una verdadera alteración a la representación política.

El artículo de Daniel Zovatto describe y compara el uso que han tenido las "instituciones de democracia directa" en los países latinoamericanos. Entre los mecanismos de democracia directa más conocidos sobresalen las consultas populares y los referendos, que se llevan a cabo a nivel nacional o local. El uso de tales mecanismos reviste especial significado en muchas democracias contemporáneas, pero en el debate latinoamericano se presentan como alternativa a la función que cumplen los partidos y frente a la democracia representativa en general. A nivel regional, la promoción de la democracia directa no ha venido siendo promovida preferentemente desde el gobierno y, en menor medida, desde la ciudadanía. De acuerdo a los datos entregados por Zovatto, de las consultas populares Ilevadas a cabo entre 1978 y el 2010, en el 61\% de ellas se impuso la posición del gobierno, y en las otras no. Pese a que los mecanismos de democracia directa han sido incorporados en los textos constitucionales de la mayoría de los países latinoamericanos, se utilizan con escasa frecuencia en el nivel nacional. La excepción a este respecto la constituye Uruguay y, en 
menor medida, Ecuador, Venezuela, Bolivia y Panamá. Cabe agregar que en la experiencia uruguaya se ha sabido combinar el uso de la democracia directa con las instituciones y prácticas propias de la democracia representativa.

La tercera sección está dedicada al liderazgo carismático y al populismo. En esta sección, María Matilde Ollier se concentra en la emergencia de liderazgos carismáticos en el peronismo. Junto con dar cuenta de la irrupción de Juan Domingo Perón, describe lo que ocurre posteriormente con Carlos Menem y Néstor Kirchner. Con Perón se logra identificar a la organización partidaria con el líder, y a este último con el pueblo. El líder se presenta como un representante de la nación; además, ejerce un poder concentrado que se orienta hacia el movimiento y el conjunto de las instituciones estatales. Desde 1989 Menem lleva a cabo una gestión gubernamental marcada por la concentración, la delegación y el decretismo, sobrepasando no sólo las atribuciones del Parlamento sino además superando el estatismo promovido por los dirigentes de su propio partido. Al igual que Perón, Menem aspira a convertirse en conductor y, desde esa condición, dirigir "la refundación de la Nación y de la unidad del pueblo". Menem, a diferencia de Perón, busca asegurar el respaldo de la opinión pública mediante la denostación de las organizaciones y partidos tradicionales. Tras las situaciones de crisis y normalización del sistema político argentino, vividas entre el 2001 y el 2003, Néstor Kirchner mantiene esos mismos rasgos. El respaldo ciudadano le permite personalizar la gestión y las decisiones gubernamentales, y tomar distancia de aquellos grupos políticos desprestigiados por la crisis de finales del 2001. En este artículo, además, se muestra cómo a partir de Kirchner el peronismo logra ampliar su radio de representación e intensificar la competencia entre las distintas facciones del partido justicialista.

Desde una perspectiva comparada, Donatella Campus describe la promoción de un discurso antipolítico por parte de líderes carismáticos que lograron Ilegar al gobierno. Este discurso se asocia a un determinado tipo de populismo, que se muestra capaz de canalizar las aspiraciones de cambio del sistema político y la crítica hacia las instituciones intermedias en general. La autora considera lo que significa la emergencia de este tipo de liderazgos para el funcionamiento de los sistemas representativos y las características asumidas como consecuencia de una mayor mediatización de la política.

En la cuarta sección, los artículos de Octavio Avendaño, Gloria de la Fuente y Mireya Dávila discuten sobre una serie de aspectos del proceso político chileno. El artículo de Avendaño describe aquellos factores estrictamente políticos que permiten entender el crecimiento electoral de la derecha durante las últimas dos décadas y que facilitaron su triunfo en enero del 2010. Por su parte, Gloria de la Fuente da cuenta de los cambios que experimenta la "matriz sociopolítica" a partir de las modificaciones que va sufriendo el sistema de representación y la función del Estado desde la segunda mitad de los años setenta. Junto con destacar los cambios introducidos en el modelo de desarrollo, describe los hitos más importantes que marcaron el proceso de transición y de recuperación democrática. Mireya Dávila examina el grado de influencia que tienen los tecnócratas en la toma de decisiones y en la definición de la política pública. Para ello, se concentra en los gabinetes ministeriales y en los subsecretarios que se suceden en el período 1990-2010. De acuerdo 
a los datos entregados por la autora, no se produce una separación muy evidente entre tecnocracia y militancia partidaria, pues tanto los ministros como los subsecretarios que fueron calificados de tecnócratas pertenecían o fueron promovidos por los partidos de la coalición gobernante en esos años.

La quinta sección está dedicada al Bicentenario a partir de un caso particular. En el único artículo que aparece en esta sección, escrito por Nora Rabotnikof, se reflexiona sobre la conmemoración del Bicentenario mexicano, cuyo proceso independentista se iniciara con el llamado Grito de Dolores, en septiembre de 1810. Tal conmemoración coincide con la celebración del Centenario de la Revolución mexicana, lo que permite entremezclar una serie de aspectos relacionados con la identidad y la memoria histórica de la sociedad. Pese a estas particularidades, muchas de las reflexiones que se llevan a cabo en su interior son perfectamente aplicables a otros países de la región. Según agrega Rabotnikof, la sociedad mexicana no sólo tiene la posibilidad de discutir acerca de la relación entre el pasado y el presente, sino también acerca de las dificultades y los riesgos del futuro, tales como la violencia organizada, el narcotráfico y la corrupción. Al mismo tiempo, deja pendiente una serie de desafíos relacionados con la construcción de una nación plural, la mayor protección de los ciudadanos y los privilegios de las élites. En suma, la sociedad mexicana presenta una serie de fragmentaciones que redefinen el sentido de la nación y que cuestionan las visiones e ideas promovidas por la historia oficial.

Finalmente, quisiéramos agradecer a los integrantes del comité organizador del XXI Congreso Mundial de Ciencia Política, Santiago 2009, que nos facilitaron los contactos y apoyaron para la realización de este número especial de la Revista. Agradecemos también la colaboración de Claudia Baeza y Javier Loyola en las labores de traducción y control de tres de los artículos aquí presentados.

\author{
Manuel Antonio Garretón \\ Presidente Comité Local \\ XXI Congreso Mundial de Ciencia Política
}

\author{
Octavio Avendaño \\ Editor Revista de Sociología \\ Universidad de Chile
}

